\title{
The Influence of Cooling System on the Fattening Pig Welfare Parameters
}

\author{
Dmitriy A. Orlov ${ }^{1}$, Thomas Jungbluth ${ }^{2}$, Konstantin V. Zhuchaev ${ }^{1}$, \\ Marina L. Kochneva1, Olga V. Bogdanova1, Nora Hammer ${ }^{2}$ and Joahim Threm²
}

\author{
${ }^{1}$ Novosibirsk State Agrarian University, 160 Dobrolyubova str., Novosibirsk 630039, Russia \\ ${ }^{2}$ University of Hohenheim,Stuttgart, Germany
}

http://dx.doi.org/10.13005/bbra/2091

(Received: 03 April 2016; accepted: 20 May 2016)

\begin{abstract}
The studies were conducted on groups of fattening pigs aged 3 to 5.5 months, which were kept in four sectors with different air cooling systems. For observation we used the animals assessment technique presented in a Welfare assessment protocol for pigs. It is revealed that the indoor air cooling method at temperatures in the control sector ranged from 19 to $26.6^{\circ} \mathrm{C}$ does not have a decisive influence on the suite of welfare parameters of fattening pigs (Fatting young pigs. in spring and summer periods closing parenthesis. Cooling method based on air inflow through underground tunnels provides a good level of ventilation, reduces the concentration of harmful gases, and ensures lower humidity as compared to control. At that, it reduces the incidence of cannibalism in pigs $(P<0.05)$. The reduction of animal fouling in sectors with a high content of harmful gases with some reduction in temperature (by $0.8-1.5^{\circ} \mathrm{C}$ ) and increase in relative humidity (by $1.3-4.3 \%$ ) is possibly due to the inhibition of general activity of animals. The authors revealed also the effect of animal feeding (wet and dry feeding systems) on the animal fouling intensity $(\mathrm{P}<\mathbf{0 . 0 5})$. The incidence of cannibalism in pigs was decreased in the farm with dry feeding system $(\mathrm{P}<0.05)$.
\end{abstract}

Key words: pigs, young fattening pigs, animal welfare, cooling system.

The main reason for the reduced utilization period of highly productive animals is that their welfare conditions at the industrial complexes are not suitable for those formed during the evolution of animal physiological characteristics ${ }^{4,5,8}$. Maintaining a comfort environment for pigs, as well as for other domestic animals, is essential for their overall welfare and the productiveness ${ }^{9,16}$.

New European technology standards in the pig breeding are set by EU Directives (91/630/ EC, 2001\93\EU, and 2001/88/EC). Improving the product quality in pig farming is directly associated

\footnotetext{
* To whom all correspondence should be addressed.
}

with reduction in the number of stressful situations in production process and provision of the welfare conditions for animals ${ }^{14}$.

Animal welfare is defined by many characteristics: appearance of the animal, its behavior, health status, as well as animal management and feeding conditions. At that, welfare of animal cannot be fully assessed on the basis of just one of these indicators ${ }^{2,9}$.

Assessing the welfare of pigs according to the European welfare assessment protocols includes parameters such as the fear of human, the condition of the body and extremities (fouling and the presence of wounds), as well as technological parameters, etc ${ }^{2}$.

The aim of this work was to determine the effect of technological factors (air cooling 
system) on the welfare parameters of pigs raised in the conditions of intensive production.

\section{MATERIALSANDMETHODS}

Studies were carried out at two zero grazing pig farms (zero grazing ) in BadenWurttemberg, (Germany) in the period from February to the end of August. Tests were conducted in groups of fattening pigs aged 3 to 5.5 months and weighing from 36 to $118 \mathrm{~kg}$. Group size in the farm \#1 ranged from 15 to 22 heads per pen depending on the size of the pen assuming 0.7 $\mathrm{m}^{2}$ per head. The hogpen was divided into 4 sectors with different air cooling systems. Each sector contained 125 heads (6 pens). The hogpen had grating floor. Pigs were fed automatically three times a day with the aid of slop feed.

Sector 1 (control) had no air cooling system;

Sector 2 was provided with air cooling system based on the cooling wall, which was made of cassettes to enable evaporation of water. The cassettes were packed into a rigid stainless steel frame. Lower part of the frame was provided with water drainage sump, while the top was equipped with tube having holes for water supply. Water, outflowing from the holes, flows along a corrugated sheet from top to bottom, wetting the panel. Dry warm air, passing through the panel, partially saturates with the moisture and transforms into cold and wet air.

Sector 3 was provided with system, where cooling of the air took place during its flow through the underground tunnels. It was continuously flowing into the hogpen through the perforated floor of the central passage.

Sector 4 was provided with mist system for water spraying several times per hour depending on the room temperature.

The group size in the farm \#2 contained 22 heads; the hogpen had grating floor; pigs were fed automatically with dry feed three times a day. The air cooled while flowing through the underground tunnels. A continuous supply of cool air to the hogpen was carried out through the perforated floor of the central passage.

Due to the fact that the ambient air temperature from March to end of August ranged from +9 to $+36^{\circ} \mathrm{C}$, the observations were grouped into two periods. In the first period (spring, from early March to late May) studies have been conducted in sectors 1,2 , and 3 , while in the second period (summer, from June to end of August) tests were carried out in the sectors 1 and 4 , as well as in the farm \#2.

To assess the animal welfare, we considered condition of the skin covering, ears and tail of the animals ${ }^{13}$, as well as the general management conditions and fouling of the cage. We used animals' assessment method presented in a Welfare assessment protocol for pigs ${ }^{2}$ with some modification to optimize the data processing process. We studied fouling of skin covering and its general condition, as well as the ears and tail condition using a special assessment scale.

\section{Determining animal fouling}

* clean (0) - no fouling;

* $\quad$ slight fouling (1) - less than $25 \%$ of the body is fouled;

* moderate fouling (2) - from 25 to $50 \%$ of the body is fouled;

* heavy fouling (3) - more than $50 \%$ of the body is fouled.

\section{Determining the status of different body parts of animals}

* $\quad$ normal (0) - no visible wounds;

* scratches (1) - availability of dry not bleeding scratches across the body surface;

* $\quad$ open wounds (2) - availability of bleeding wounds of any size;

* $\quad$ necrosis/bitten off (3) - lack of significant portion of the ear.

The indoor microclimate parameters were assessed every two weeks during the whole period of research followed by subsequent calculation of average indicators. The concentration of gases $\left(\mathrm{CO}_{2}, \mathrm{NH}_{3}, \mathrm{CH}_{4}\right)$ was determined using a multichannel analyzer providing around-the-clock measurements every 27 seconds. Measured data were transmitted to the computer. To assess the effect of microclimate on animal welfare, we used data obtained over the past month of animal management.

Experimental data were subjected to statistical processing by Fisher's angular transformation and Kruskal-Wallis criterion methods.

\section{Research results}

Animal welfare is defined by many 
characteristics such as appearance of the animal, its behavior, health status, as well as management and feeding conditions ${ }^{2}$. Failure in required management conditions of the pigs leads to discomfort of the animals ${ }^{9,16}$.

One of the most important factors

Table 1. The indoor microclimate conditions for fattening pigs in the spring

\begin{tabular}{lccc}
\hline Indicator & \multicolumn{3}{c}{ Farm \#1 } \\
\cline { 2 - 4 } & Sector 1(control) & Sector 2 & Sector 3 \\
\hline Gas concentration: & & & \\
Carbon dioxide, \% & $0.2 \pm 0.001$ & $0.21 \pm 0.001^{* *}$ & $0.17 \pm 0.001^{* *}$ \\
Ammonia, $\mathrm{mg} / \mathrm{m}^{3}$ & $19.93 \pm 0.23$ & $20.05 \pm 0.2^{* *}$ & $16.18 \pm 0.19^{* *}$ \\
Methane, $\mathrm{mg} / \mathrm{m}^{3}$ & $107.31 \pm 1.16$ & $94.76 \pm 0.99^{* *}$ & $32.87 \pm 0.31^{* *}$ \\
Average indoor temperature, ${ }^{\circ} \mathrm{C}$ & $19.0 \pm 0.38$ & $19.77 \pm 0.12$ & $20.57 \pm 0.56$ \\
Relative indoor humidity, $\%$ & $63.67 \pm 4.06$ & $60.67 \pm 3.48$ & $59.33 \pm 1.45$ \\
\hline
\end{tabular}

Table 2. Status of the skin covering and various body parts in fatted pigs in the spring, \%

\begin{tabular}{|c|c|c|c|c|c|}
\hline $\begin{array}{l}\text { Indicator } \\
1\end{array}$ & 2 & $\begin{array}{l}\text { Points } \\
3\end{array}$ & $\begin{array}{c}\text { Sector } 1 \text { (control) } \\
4\end{array}$ & $\begin{array}{c}\text { Sector } 2 \\
5\end{array}$ & Sector 3 \\
\hline \multirow[t]{4}{*}{ Body fouling } & Clean & 0 & 11.5 & $23.5^{*}$ & $0.8^{* *}$ \\
\hline & Slight fouling & 1 & 84.6 & $69.8 * *$ & $71.1 * *$ \\
\hline & Moderate fouling & 2 & 3.9 & 6.7 & $28.1 * *$ \\
\hline & Heavy fouling & 3 & 0 & 0 & 0 \\
\hline Total, \% & & 100 & 100 & 100 & \\
\hline \multirow[t]{3}{*}{ Skin condition } & Normal & 0 & 2.6 & 6.7 & 4.1 \\
\hline & Scratches & 1 & 92.3 & 85.7 & 89.3 \\
\hline & Open wounds & 2 & 5.1 & 7.6 & 6.6 \\
\hline Total, \% & & 100 & 100 & 100 & \\
\hline \multirow[t]{4}{*}{ Ears condition } & Normal & 0 & 16.6 & 16.8 & $28.1^{*}$ \\
\hline & Scratches & 1 & 79.5 & 75.6 & $67.8 *$ \\
\hline & Open wounds & 2 & 1.3 & $6.7^{*}$ & 4.1 \\
\hline & Necrosis / bitten off & 3 & 2.6 & 0.9 & 0 \\
\hline Total, \% & & 100 & 100 & 100 & \\
\hline \multirow[t]{3}{*}{ Tail condition } & Normal & 0 & 41.0 & 46.2 & $56.2 *$ \\
\hline & Scratches & 1 & 55.1 & 46.2 & $40.5^{*}$ \\
\hline & Open wounds & 2 & 3.9 & 7.6 & 3.3 \\
\hline$\%$ & & 100 & 100 & 100 & \\
\hline
\end{tabular}

Note: the comparison with the control sector; the differences are significant at the level: $* \mathrm{P}<0.05$; $* * \mathrm{P}<0.01$.

Table 3. The microclimate in the fattening pigs hogpen during the summer period

\begin{tabular}{lcc}
\hline Indicator & Sector 1 (control) & Sector 4 \\
\hline Gas concentration: & & \\
Carbon dioxide, $\%$ & $0.12 \pm 0.0009$ & $0.11 \pm 0.001^{* *}$ \\
Ammonia, $\mathrm{mg} / \mathrm{m}^{3}$ & $11.08 \pm 0.1$ & $9.24 \pm 0.16^{* *}$ \\
Methane, $\mathrm{mg} / \mathrm{m}^{3}$ & $55.26 \pm 0.59$ & $50.7 \pm 0.81^{* *}$ \\
Average indoor temperature, ${ }^{\circ} \mathrm{C}$ & $26.6 \pm 1.86$ & $25.8 \pm 1.74$ \\
Relative indoor humidity, $\%$ & $61.25 \pm 3.01$ & $66.7 \pm 1.2$ \\
\hline
\end{tabular}


influencing the animal condition is the temperature of the environment. Dynamics of the pigs' welfare parameters is presented in Fig.1. The fluctuations of the indoor air temperature in the control sector corresponded in general to outdoor temperature fluctuations. Among the considered indicators, fouling of the surface of the pig body (torso body) was the parameter most strongly influenced by the temperature change of the environment. The maximum air temperature in the hogpen used for management of fattening pigs should be $20^{\circ} \mathrm{C} 7,11$. Based on tabular data, we can judge that the average temperature across all sectors was slightly above the established norm. The highest average

Table 4. Condition of the skin and different body parts in fattening pigs during the summer period, \%

\begin{tabular}{llccc}
\hline Indicator & & Points & Sector 1 (control) & Sector 2 \\
\hline \multirow{2}{*}{ Body fouling } & Clean & 0 & 1.0 & 2.4 \\
& Slight fouling & 1 & 81.8 & 76.8 \\
& Moderate fouling & 2 & 17.2 & 20.8 \\
& Heavy fouling & 3 & 0 & 0 \\
Total, \% & & 100 & 100 & \\
Skin condition & Normal & 0 & 1.0 & 0.8 \\
& Scratches & 1 & 98.0 & 2.8 \\
Total, \% & Open wounds & 2 & 1.0 & 2.4 \\
Ears condition & Normal & 100 & 100 & $24.8^{*}$ \\
& Scratches & 0 & 13.1 & 2.4 \\
& Open wounds & 1 & 82.9 & 1.6 \\
Total, \% & Necrosis / bitten off & 3 & 2.0 & $66.4^{*}$ \\
Tail condition & Normal & 100 & 2.0 & $30.4^{*}$ \\
& Scratches & 0 & 100 & 3.2 \\
Total, \% & Open wounds & 2 & 54.6 & \\
\hline
\end{tabular}

Table 5. Fattening pig welfare parameters in different farms with the similar air cooling systems, \%

\begin{tabular}{llccc}
\hline Indicator & & Points & Farm \#1 (sector 4) & Farm \#2 \\
\hline Body fouling & Clean & 0 & 0 & 0.6 \\
& Slight fouling & 1 & 68.6 & $79.5^{*}$ \\
& Moderate fouling & 2 & 29.8 & $19.9^{*}$ \\
& Heavy fouling & 3 & 1.6 & 0 \\
Total, \% & & 100 & 0.6 \\
Skin condition & Normal & 0 & 06.8 & $99.4^{*}$ \\
& Scratches & 1 & 3.2 & 0 \\
Total, \% & Open wounds & 2 & 100 & \\
Ears condition & & 100 & 16.1 & $9.0^{*}$ \\
& Normal & 0 & 80.7 & $88.6^{*}$ \\
& Scratches & 1 & 2.4 & 0.6 \\
Total, \% & Open wounds & 2 & 0.8 & 1.8 \\
Tail condition & Necrosis / bitten off & 3 & 100 & 66.9 \\
& & 100 & 62.1 & 32.5 \\
Total, \% & Normal & 0 & 31.5 & $0.6^{* *}$ \\
\hline
\end{tabular}


air temperature was noted in the $3^{\text {rd }}$ sector $(20.57 \pm$ $0.96^{\circ} \mathrm{C}$ ) (Table 1$)$.

We can observe the inverse relationship of temperature and concentration of gases (Fig. 2). Thus, at the time of lowering the indoor and outdoor temperature, the gas concentration sharply increased, and vice versa. This may be due to the fact that during a period of high indoor temperatures, more intense ventilation removes a greater amount of heated air from the indoor space together with the greater amount of harmful gases.

Compliance with the temperature regime results in comfortable welfare of pigs in thermoneutral zone and, as a result, animals do not spend energy on searching for a cool place. The behavior of the pigs is a good indicator of temperature conditions. If fouled pig, stretched out, lies in the defecation zone, this indicates that the animal is experiencing discomfort and feeling hot ${ }^{1}$.

The cooling systems used in sectors 2 and 3, did not significantly reduce the temperature in the spring observation period.

The lowest content of carbon dioxide, ammonia and methane was recorded in the sector 3 (Table 1). Highest level of ammonia and carbon dioxide were observed in the sector 2 . The highest levels of methane as well as humidity were recorded in the control sector.

Variance analysis of the animal fouling has shown that the air cooling system had a significant impact on the intensity of the animal skin fouling $(\mathrm{P}<0.001)$.

In sector 3 pigs had a greater intensity of fouling, i.e. the percentage of clean and slightly fouled animals was lower $(\mathrm{P}<0.01)$ than in the control (Table 2). In sector 2 animals were cleaner, the proportion of clean animals was significantly higher $(\mathrm{P}<0.05)$, while number of animals with slight fouling was lower than in the control sector $(\mathrm{P}<0.01)$.

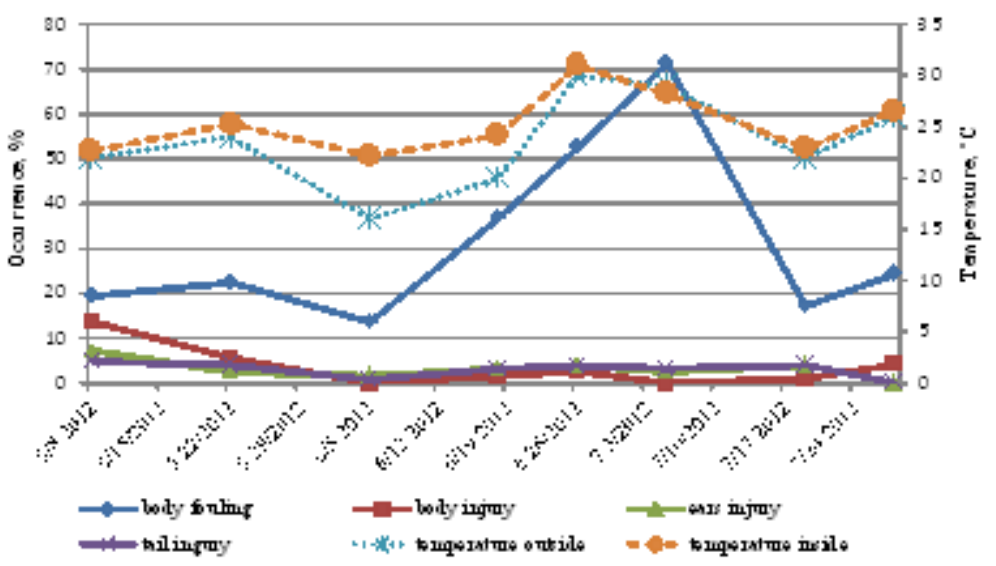

Fig. 1. Fattening pigs condition dynamics (sector 1 - control)

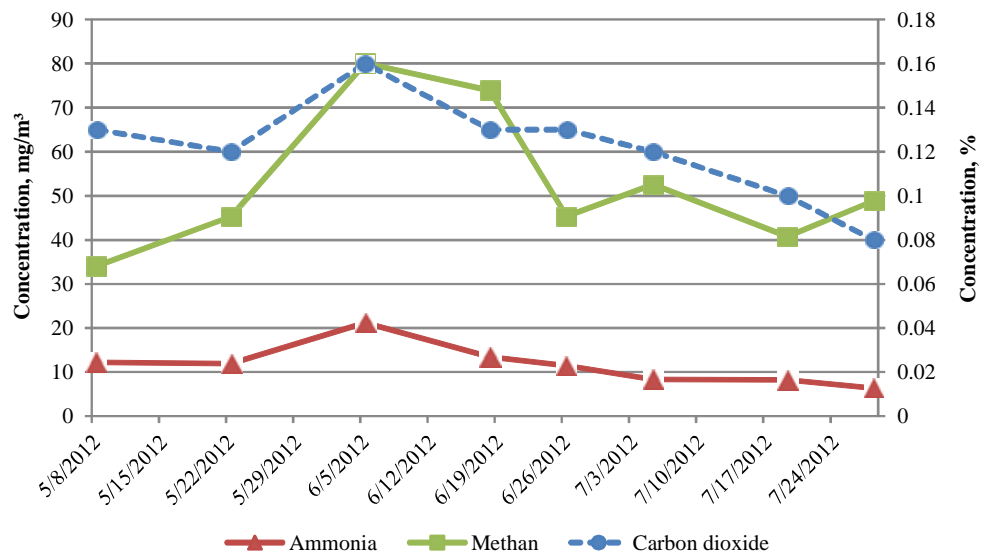

Fig. 2. Gas concentration dynamics in the control sector (Sector 1). 
Variance analysis on availability of wounds on the skin, ears and tail revealed no significant influence of air cooling system on the studied characteristics.

At that, proportion of the animals without injury on the ears in sector 3 was significantly higher than that in the control sector $(\mathrm{P}<0.05)$, whereas the percentage of animals with open wounds on the ears in sector 2 was higher as compared to the control sector $(\mathrm{P}<0.05)$.

The condition of the tail is an important indicator of animal welfare ${ }^{12}$. In sector 3 , the proportion of animals with tail lesions and scratches was smaller than in the control sector $(\mathrm{P}<0.05)$.

Research conducted in the summer has shown that the mist cooling system does not provide temperature reduction and in addition increases the indoor humidity (Table 3).

The concentration of carbon dioxide, ammonia, and methane did not exceed the maximal admissible concentration (MAC), though was less in sector $4(\mathrm{P}<0.01)^{7,11}$.

During the summer period, both indoor and outdoor temperatures may be extremely high that can cause heat-stress in animals ${ }^{10}$. Fouling of the animals may serve the indicator of their elevated body temperature ${ }^{1}$.

Variance analysis of the data revealed no significant effect of air cooling system on the fattening pig welfare in summer.

At the same time, significant differences were identified between sectors in terms of incidents of wounds on the ears and tail (Table 4). In this context, sector 4 was more unharmed $(\mathrm{P}<0.05)$.

The comparative characteristic of animal condition in two farms with the same air cooling system, but different feeding systems and population (stocking density?) has shown that during extremely high ambient outdoor temperatures $\left(32^{\circ} \mathrm{C}\right)$, such air cooling system also did not provide indoor temperature at the optimum level.

The assessment of the animal condition has shown that in farm \#2 animals were relatively cleaner, the proportion of slightly fouled animals was higher, while proportion of moderately fouled animals was lower than in sector $4(\mathrm{P}<0.05)$ (Table 5). Thus, the effect of the "farm" factor was revealed with regard to animals cleanliness
$(\mathrm{P}<0.05)$. At elevated temperatures, animals in the farm \#2 were cleaner $(\mathrm{P}<0.05)$. Obviously, this is due to the dry feeding system.

No significant differences were detected in terms of availability of serious wounds on the skin and ears. A significant reduction in the occurrence of wounds on the tails in the farm \#2 is associated may be with dry feeding system.

\section{DISCUSSION}

Among the environmental factors, significant impact on the animal welfare has a microclimate inside the hogpen: temperature and humidity, speed of air movement, the concentration of harmful gases, contamination of indoor environment with microorganisms, dust level, and illumination intensity ${ }^{7,8,9}$.

The increase of temperature above comfort level leads to reduced feed intake and deterioration of food conversion, and consequently, the drop in average daily gains ${ }^{10}$.

The excessive concentration of ammonia, carbon dioxide and hydrogen sulfide is accompanied by high concentrations of pathogenic microorganisms ${ }^{7}$. Air pollution not only worsens the ecological situation, but also, as an environment favorable to the growth of bacteria, inhibits the animals, causing stress, functional health problems, which lead to the culling of the animals ${ }^{11}$, reduce growth rates, weaken reproductive function, and increase the cost of veterinary $\operatorname{care}^{1,3}$. The increase of indoor air temperature and humidity may lead to the increase in the number of animals with a high intensity of fouling. This results in a higher risk of morbidity ${ }^{2}$, ${ }^{9}$ and reduction in productivity of pigs by $20-30 \% 8$. Air humidity increases when using air cooling system by water atomization, as well as wet feeding and manure hydro-flushing ${ }^{9}$.

In our studies, the lowest content of carbon dioxide, ammonia, and methane in the spring period was recorded in sector 3 with the cooling system based on air flow through the underground tunnels. The highest levels of ammonia and carbon dioxide were noted in sector 2 with the cooling wall. The highest levels of methane as well as the highest humidity were recorded in the control sector. Variance analysis of the data on the animals fouling showed that the air cooling system during 
this period had a significant impact on the intensity of skin fouling $(\mathrm{P}<0.001)$. Thus, in sector 2 the animals were cleaner, the proportion of clean animals was significantly higher $(\mathrm{P}<0.05)$, while the number of animals with slight fouling was lower than in the control sector $(\mathrm{P}<0.01)$ and sector 3 . Lower fouling intensity of animals in sector 2 , while at the better gas composition in the sector 3 , is due to the fact that 1 ) the temperature in the sector 2 was slightly below ${ }^{6} ; 2$ ) the animals activity was somewhat suppressed under the conditions of high concentration of harmful gases ${ }^{3}$. At the same time, fattening young pigs in sector 3 was more unharmed in terms of wounds on the ears and the tail as compared with the animals in control sector $(\mathrm{P}<0.05)$ that confirms the importance of the harmful gases concentration on the incidence of cannibalism in pigs $^{3,15}$.

At a higher indoor temperature, all other microclimate parameters were somewhat worse in the summer period. This may be due to the fact that more intense ventilation in this period removes a greater amount of heated indoor air together with harmful gases.

In the summer, in sector 4, provided with the cooling system based on water atomization as well as wet feeding system, the humidity was slightly higher than in the control sector, though not exceeding the $\mathrm{MAC}^{7}$. This did not entaile the deterioration of the animal welfare assessment.

During the summer observation period, almost all microclimate parameters in sector 4 were somewhat worse as compared to the control sector, except of air humidity (Table 4). However, animals in sector 4 were less trouble-free in terms of incidence of scratches on the skin and ears as well as wounds on the tail, than the animals in the farm \#2 $(\mathrm{P}<0.05)$. Perhaps this is due to the animal feed system (wet feeding in sector 4 provokes cannibalism).

\section{CONCLUSIONS}

1. The indoor air cooling method at temperatures in the control sector, ranged from 19 to $26.6^{\circ} \mathrm{C}$, has no decisive influence on the fatting pig welfare indicators in spring and summer periods.

2. The use of the cooling method, based on air flow through the underground tunnels, provides a good level of ventilation, reduces concentration of harmful gases, and lowers humidity as compared to control. This definitely reduces the incidence of cannibalism in pigs.

3. Reduction of animal fouling in sectors with high content of harmful gases with some reduction in temperature (by $0.8-1.5^{\circ} \mathrm{C}$ ) and increase in relative humidity (by 1.3-4.3\%) is, possibly, due to the inhibition of general activity of the animals.

\section{REFERENCES}

1. Armstrong, D., "Environmental Management for Healthy Pig Production,” Meat and Livestock Commission, 2004; 4: 9-14.

2. Blokhuis, H.J., "Welfare Quality ${ }^{\circledR}$ Assessment Protocol for Pigs,” Uppsala 2009; 122.

3. Donham, K.J., "Association of Environmental Air Contaminants with Disease and Productivity in Swine,” Am. J. Vet. Res., 1991; 52(10): 1723-1730.

4. Dunkan, I.J.H., “The Welfare of Farm Animals: an Ethological Approach,” Scientific Program, 1983; 71: 317-326.

5. Gart, V.V., Zhuchaev, K.V., and Petukhov, V.L., "The Genetic Relationship of Pig Immune Responsiveness with Expression of Stress Susceptibility,” Proceedings of the XXIII Int. Conf. on Animal Genetics, University of Bern, pp. 43-45.

6. Hacker, R.R., et al., "Factors Affecting Excretory Behavior of Pigs,” J. Anim. Sci., 1994; 72: 1455-1460.

7. Jacobson, L.D., “Air Quality in Animal Structures,” Biosystems and Agricultural Engineering Department, University of Minnesota, USA, 2008.

8. Lyons, C.A.P., et al., “A Comparison Productivity and Welfare of Growing Pigs in Four Intensive Systems,” Livestock Production Science, 1995; 43: 265-274.

9. McGlone, J.J., Pond, W., "Pig Production: Biological Principles and Applications,” Delmar Learning, 2003; 395 p.

10. McGlone, J.J., "Effect of Heat and Social Stressors and Within-pen Weight Variation on Young Pig Performance and Agonistic Behavior," J. Anim. Sci., 1987; 65: 456-462.

11. Mihina, S., "Concentration of Harmful Gases in Poultry and Pig Houses,” Animal Science Papers and Reports, 2012; 30: 395-406. 
12. Temple, D., et al., "Assessment of Animal Welfare through Behavioral Parameters in Iberian Pigs in Intensive and Extensive Conditions," Applied Animal Behavior Science, 2011; 131: 29-39.

13. Pflanz, W. et al., "Comprehensive Assessment of Innovative Pig Fattening Methods in a Field Study,” Landtechnik, 2004; 59: 274-275.

14. Velarde, A., Dalmau, A., "Animal Welfare Assessment at Slaughter in Europe: Moving from
Inputs to Outputs,” Meat Science, 2012; 92: 244-251.

15. White, M., “Skin Lesions in Pigs,” Farm Animal Practice, 1999; 21: 20-29.

16. Zhuchaev, K.V., et al., "Effect of Housing Conditions with Environment Enrichment on Physiological State of Yong Pigs when Weaning from Sows," Russian Agricultural Sciences, 2014; 40(6): 475-478. 